asylum would act as manager of this hospital, but appear in the capacity of medical man only when desired by the hospital physician. All cases deemed curable would be received into this hospital-idiots, imbeciles, and hopeless senile and chronic cases going direct to the asylum. Cases not recovering, or showing signs of probable recovery within a reasonable time, would be transferred to the care of the asylum authorities to make room for fresh cases.

A small hospital of this kind, built on the generally ample grounds of our present asylums, would not cost much, and would soon become a source of profit to the ratepayers; prcvent to a great extent the now ever-recurring necessity of enlarging asylums-in fact, tend to keep the insane population within reasonable limits.

Here the physician would be a physician in reality as well as in name. It would be his life's work to treat his patients and study their diseases. He would not have many and grave business matters constantly weighing on his mind. He would not profit by a low rate per week, nor suffer through a high one. $\mathrm{He}$ would be a physician pure and simple, whose sole interest would be the recovery of his patients.

There are difficulties in the way of the establishment of hospitals like that sketched above, but these difficulties are not great; they are difficulties which must and will soon be overcome. The day of hospital treatment of the insane is fast approaching, and until that day arrives psychological medicine must remain in its present backward state, and the asylum superintendent receive the opprobrium which the system and not the man deserves.

A Glance at Lunacy in Spain. By F. A. JeLLY, M.B., Assistant Medical Officer, Wonford House Asylum, Exeter.

While on a short visit to Madrid some little time ago I determined to find out how Spain treated her lunatics. I visited the public asylum of Santa Isabel at Leganes, but was refused admission, as there was no resident physician, and the village doctor, who was supposed to make his rounds at 9 a.m., was away! A friend, however, kindly gave me an introduction to the leading Spanish alienist, Dr. D. José Esquerdo, who, he told me, had a private asylum at Carabanchel, and thither I went. This little village is about three miles from Madrid, and easily reached by tramcar. 
Dr. Esquerdo's asylum stands on an elevated, sandy plain, about 200 métres from C. Alto, and is approached by a steep, rugged road. In external appearance it is most unlike our ideas of a private asylum : not a tree to be seen for miles, and the whole block of buildings is enclosed by wooden palisades.

On passing through a gate I came into an attempt at a garden, consisting of a few stunted shrubs striving for existence in a wilderness of sand and rubbish. After ringing several times at a primitive bell suspended near a door, and being gazed at through an adjacent barred window, I was admitted into a small unfurnished vestibule, where I caught sight of statuettes of Pinel, Esquirol, and one or two other alienists. I was then led into a large reception-room, painfully Spanish in its dirt and bareness, somewhat relieved, however, by a few well-known coloured illustrations from the "Graphic." I was shortly joined by a gentleman, who regretted that his uncle, Dr. José Esquerdo, was not at home, but he was his nephew and senior resident, and would be most happy to take me round and answer any questions. I should here like to bear my testimony to the frank kindness and hospitality of Dr. Santiago Esquerdo, as these qualities are very rare among Spaniards. On my stating that I wished to see the ordinary management of the place, he invited me at once to join himself and the male patients at their midday meal, and, taking me through a dark room in which were a few invalids eating, he ushered me with much Spanish formality into a fine markle-floored dining-hall that would put many Continental hotel dining-rooms to the blush. Light came in through stained glass windows, and at the further end was a high dais separated from the rest of the hall by balustrades. The majority of the patients sat at two tables placed in the centre of the room, and presided over by the junior resident and the dispenser, each of whom, by the way, like Dr. Santiago, wore a sort of grey uniform and a peak cap with gold band round it. We sat at a table, placed transversely on the dais, with about eight of the better patients, so that everyone was under the eye of the senior medical man. A very good Spanish meal was served, the well-known puchero forming the principal item of the menu. The patients, though very untidy and forbidding, for the most part behaved admirably. Spaniards are not, when sane, very cleanly eaters, and I will not attempt to describe the various methods of disposing of their food 
adopted by these poor lunatics. They appeared to enjoy the meal, and after the usual figs and raisins many of them lit cigarettes, while Dr. Santiago and I adjourned to his sanctum, a small room into which no light or air could be admitted without opening a large door which led on to the high road! Such, however, are many of the rooms, even in the largest towns of Spain, only one certainly expected something better in a large private asylum. IVe had a very agreeable chat, however, over our coffee, Dr. Santiago showing me, with pride, about half-a-dozen books on mental diseases, all French except one, which was a Spanish translation of one of Dr. Maudsley's works. The Spaniards are not a literary people, and indeed it is marvellous how they obtain any knowledge of scientific progress at all, as one never comes upon a man reading anything but a newspaper. On enquiring as to the rules of admission to the asylum I was shown some manuscript papers, and it was explained that a letter of application from the friends or relatives was required, and one medical certificate. The rest of the paper was supposed to be filled with the history of the case, but, as he said, "I am a little behindhand with my work;" and indeed there only appeared one sheet anything like filled up! The patients are divided into three classes, according to the fees paid, the first paying at the rate of $\$ 240$ per annum, the second $\mathfrak{E 1 4 4}$, and the third $\mathfrak{2 7 2}$. The distinctions as to accommodation and food are most clearly given in the small prospectus, the first class, among other privileges, being permitted to go out twice a week in the carriage.

The Asylum has now been in existence for five or six years, and contained 88 males and 33 female patients; great additions were being made to it, so that $I$ did not see it at advantage. Dr. José Esquerdo, when in residence, occupies the central block of buildings, which is surmounted by a tower fitted with glass all round, and "here," said Dr. Santiago, in most flowery Spanish, as we gazed on the exterior, "Dr. Esquerdo sits continually to watch the patients and to give to the world those observations which are calculated to shed a brilliant light on the obscure treatment of mental disease." I could only bow and inwardly regret that a few rays of the brilliant light had not shone over England!

From this central block extend the male department on one side and the female block and chapel on the other, the whole forming three sides of a square. Each block is two stories high. The room I had been shown into at the first 
proved to be the general sitting-room for the gentlemen, and here I came upon a fine-looking Englishman, who had almost forgotten his native language, suffering from general paralysis. According to Dr. Santiago, there were about eleven males suffering from that disease in the asylum, and one female.

On the same floor were two padded rooms, the small windows of which were filled in with glass, tinted-orange and blue respectively; but after a close study of the effects of coloured glass on the patients, their results were vil. Adjoining these rooms was a small, dingy recreation-room, but I observed a large billiard and reading-room in process of building. The bedrooms, for the most part, were upstairs, one attendant sleeping at either end of the gallery, except in the case of patients of the first class, who had an attendant sleeping in a windowless den off their bedroom.

The female side differed little from the male, except, I think, it was dirtier, and the patients looked more miserable, except one lady, a kleptomaniac, who was seated like a Queen in the midst of an accumulation of well-sorted rubbish.

There were about four patients under restraint, and I mention this because the methods adopted were most primitive, and, I may say, inhuman. One poor fellow, I remember, had three broad straps buckled round himself and the bed, besides huge ropes knotted and twisted round him in the most hideous manner, being effectually prevented from moving a single joint. Dr. Santiago told me they did not believe much in drug treatment; and I gathered that the dispenser had an easy time of it.

Mass is performed daily in the little chapel, but as attendance is not compulsory, few are orthodox. There were no out-door amusements provided for the patients, but I understood that a wall was soon to be erected for the Spanish Juego á Pelota, a game resembling our " fives."

I may state, also, that Dr. Esquerdo has a country house, called "The Paradise," at Villajoyosa, about five leagues from Alicante, and several patients are taken down there every summer.

I have now tried to give a glimpse of the arrangement of a private asylum in Spain; and though, as I have hinted, there was much that grated on our ordinary ideas of cleanliness, order, and the treatment of the patients, still we must remember that the patients and staff were Spaniards, and I think it is a hopeful sign that such a place exists in such a country. I regret greatly that I was unable, during my 
short visit to Spain, to see through a public asylum; but during other interviews with Dr. S. Esquerdo, and also with his courteous uncle, I gathered a little further information that I think may be of interest.

The Spanish alienists boast that the first asylum in the world was erected in Spain, in the year 1408, and a monk, Fray Jofre Gilbert, gets the credit of having awoke the nation to a sense of the importance of caring for the hitherto neglected insane; so that during the fifteenth century four asylums were erected in various parts of the Peninsula. Now about thirty exist, the most celebrated being that of NuevaBelen, near Barcelona. The superintendent of this Institution is Dr. D. Juan Gine y Partagas, the writer of the only original work on insanity in the Spanish language, from which I have taken the following classification of mental diseases, which is said to resemble that of Guislain, but which seems to me to be one of the most unintelligible that has ever been drawn up :-

1. Melancholia, defined as pathological emotion of sadness or moral grief, consisting in depression, uneasiness, fear or terror.

2. Ecstasy, defined as suspension of the functions of sensibility, mobility and intelligence, the patients appearing as statues.

3. Mania.-Pathological emotion, with exaltation of one or more functions of the mind, characterized by a state of agitation, exaggeration, together with exaltation and agitation of the hostile passions.

4. Locura or Madness. - An emotional state, in which the patient finds himself irresistibly impelled by a whimsical will to commit acts which do not bear in themselres the characters of an active passion. It is a monomania of action without raving ideas!

5. Delirium.-Notable aberration of the intellect; error of judgment and disquietude of the ideas in a chronic form.

6. Dementia.-Weakness or more or less complete obliteration of the moral and intellectual faculties, frequently accompanied with lesions of mobility !

These six primary divisions, with the exception of ecstrasy, are split up into various minor ones, particularly mania and locura, which have 17 and 16 sub-divisions respectively. Some of these, such as "ambitious mania," "mania of vanity," “ barking madness " and " mewing madness," seem somewhat superfluous. 
I may just state, in conclusion, that there exists an Association, termed the Spanish Frenopathic Academy, which resembles somewhat our Medico-Psychological Association, only the former contains very few members.

I fear this glance at Lunacy in Spain is presented in a very imperfect and disconnected manner, but if it stimulate any of the members of this department, while taking a holiday amid the historic cities of Spain, to visit and so encourage the Spanish alienists, I think they will certainly not regret the time so spent; and, at any rate, in Madrid, I can assure them of a hearty welcome from Dr. D. José Manuel Esquerdo.

\section{CLINICAL NOTES AND CASES.}

A Case of Imbecility with Well-marked Hereditary History. By Fletcher Beach, M.B., M.R.C.P., Medical Superintendent Darenth Asylum.

Hereditary predisposition is well known to play an important part in the production of imbecility, and as this predisposition can be traced through four generations in the following case, I have thought it worthy of being placed on record:-

G. B., aged 15, was admitted into the Clapton Asylum on May 12th, 1875, with the following history:-The patient's great-grandfather was " not bright." The grandfather was very reserved, and the grandmother excitable and queer. The father of the patient was irritable, excitable, bad-tempered, and formerly intemperate. The eldest children of two brothers of the father are affected in their intellect in the same way as the patient, and the eldest daughter of the father's sister is queer and excitable. The patient, G. B., was born paralysed on the left side, and is excitable at times. When three weeks old he had a fit, and the fits continued until he was 11 years old. He was an imbecile who made little progress in school in consequence of his paralysis and difficulty of speech, but did fairly well in the shoemaker's shop. Eleven of his brothers and sisters died of convulsions during teething, and one was paralysed in the right arm.

In the first generation, then, we have weak-mindedness ; in the second a peculiarity of temperament which caused the patient's grandfather to be "very reserved." As a result of his marriage with a person who is "excitable and 